\title{
Article \\ Pericoronary Adipose Tissue Attenuation Is Associated with High-Risk Plaque and Subsequent Acute Coronary Syndrome in Patients with Stable Coronary Artery Disease
}

\author{
Jeremy Yuvaraj ${ }^{1}$, Andrew Lin ${ }^{2}$, Nitesh Nerlekar ${ }^{1}$, Ravi K. Munnur ${ }^{1}$, James D. Cameron ${ }^{1}$, Damini Dey ${ }^{2} \mathbb{D}$, \\ Stephen J. Nicholls ${ }^{1,3}$ and Dennis T. L. Wong ${ }^{1, *}$ \\ 1 Monash Cardiovascular Research Centre, Monash University and MonashHeart, Clayton, VIC 3800, Australia; \\ jeremy.yuvaraj@gmail.com (J.Y.); nitesh.nerlekar@gmail.com (N.N.); kiran.munnur@gmail.com (R.K.M.); \\ james.cameron@monash.edu (J.D.C.); Stephen.Nicholls@monashhealth.org (S.J.N.) \\ 2 Biomedical Imaging Research Institute, Cedars-Sinai Medical Center, Los Angeles, CA 90048, USA; \\ andrewklin@gmail.com (A.L.); Damini.Dey@cshs.org (D.D.) \\ 3 South Australian Health and Medical Research Institute, Adelaide, SA 5000, Australia \\ * Correspondence: drdenniswong@yahoo.com.au; Tel.: +61-3-9695-6666
}

\section{check for}

updates

Citation: Yuvaraj, J.; Lin, A.; Nerlekar, N.; Munnur, R.K.; Cameron, J.D.; Dey, D.; Nicholls, S.J.; Wong, D.T.L. Pericoronary Adipose Tissue Attenuation Is Associated with High-Risk Plaque and Subsequent Acute Coronary Syndrome in Patients with Stable Coronary Artery Disease. Cells 2021, 10, 1143. https://doi.org/ 10.3390/cells10051143

Academic Editor: Sanjay Patel

Received: 30 March 2021

Accepted: 6 May 2021

Published: 10 May 2021

Publisher's Note: MDPI stays neutral with regard to jurisdictional claims in published maps and institutional affiliations.

Copyright: (c) 2021 by the authors. Licensee MDPI, Basel, Switzerland. This article is an open access article distributed under the terms and conditions of the Creative Commons Attribution (CC BY) license (https:/ / creativecommons.org/licenses/by/ $4.0 /)$.

\begin{abstract}
Background: High-risk plaques (HRP) detected on coronary computed tomography angiography (CTA) confer an increased risk of acute coronary syndrome (ACS). Pericoronary adipose tissue attenuation (PCAT) is a novel biomarker of coronary inflammation. This study aimed to evaluate the association of PCAT with HRP and subsequent ACS development in patients with stable coronary artery disease (CAD). Methods: Patients with stable CAD who underwent coronary CTA from 2011 to 2016 and had available outcome data were included. We studied 41 patients with HRP propensity matched to 41 controls without HRP (60 \pm 10 years, $67 \%$ males). PCAT was assessed using semi-automated software on a per-patient basis in the proximal right coronary artery $\left(\mathrm{PCAT}_{\mathrm{RCA}}\right)$ and

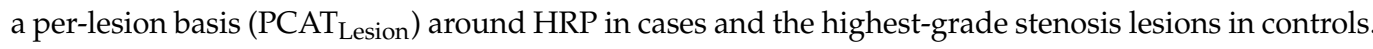
Results: PCAT $_{\mathrm{RCA}}$ and $\mathrm{PCAT}_{\text {Lesion }}$ were higher in HRP patients than controls $\left(\mathrm{PCAT}_{\mathrm{RCA}}:-80.7 \pm\right.$ $6.50 \mathrm{HU}$ vs. $-84.2 \pm 8.09 \mathrm{HU}, p=0.03$; PCAT $_{\text {Lesion }}:-79.6 \pm 7.86 \mathrm{HU}$ vs. $\left.-84.2 \pm 10.3 \mathrm{HU}, p=0.04\right)$, and were also higher in men (PCAT $\mathrm{RCA}:-80.5 \pm 7.03 \mathrm{HU}$ vs. $-86.1 \pm 7.08 \mathrm{HU}, p<0.001$; $\mathrm{PCAT}_{\text {Lesion: }}$ : $-79.6 \pm 9.06 \mathrm{HU}$ vs. $-85.2 \pm 7.96 \mathrm{HU}, p=0.02$ ). Median time to ACS was 1.9 years, within a median

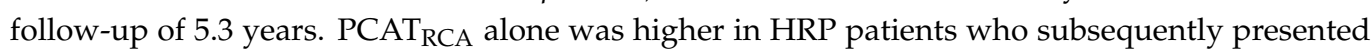
with ACS $(-76.8 \pm 5.69 \mathrm{HU}$ vs. $-82.0 \pm 6.32 \mathrm{HU}, p=0.03)$. In time-dependent analysis, ACS was

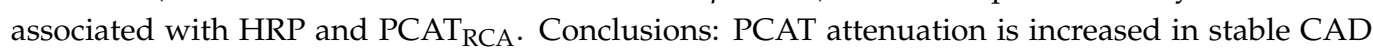
patients with HRP and is associated with subsequent ACS development. Further investigation is required to determine the clinical implications of these findings.
\end{abstract}

Keywords: coronary computed tomography angiography; atherosclerosis; coronary artery disease; high-risk plaque; acute coronary syndrome; pericoronary adipose tissue

\section{Introduction}

Approximately 50\% of acute coronary syndromes (ACS) arise from the rupture of non-occlusive coronary lesions [1,2]. Many of these lesions have features which predispose them to rupture and are termed high-risk plaques (HRP). Coronary computed tomography angiography (CTA) is a widely used non-invasive imaging modality which can reliably assess HRP features [3]. Importantly, the presence of HRP in patients with stable coronary artery disease (CAD) is associated with an increased prospective risk of ACS [4,5], highlighting the potential prognostic value of HRP detection on imaging.

Chronic vascular inflammation plays a key role in atherogenesis and atherosclerotic plaque rupture. Pericoronary adipose tissue (PCAT) attenuation is a novel marker of coronary inflammation on coronary CTA, capturing changes in adipocyte size and lipid 
accumulation caused by inflammatory mediators from the vascular wall [6]. Measurement of PCAT around the proximal RCA represents a standardised and prognostically validated per-patient metric [7-10]. PCAT attenuation can also be quantified around identifiable coronary lesions as a dynamic marker of coronary inflammation $[6,7,11]$. While increased PCAT attenuation has been reported surrounding HRP [12-14], few studies have systematically evaluated the association between ACS and PCAT attenuation in patients with HRP. We sought to perform a per-patient and per-lesion level analysis of PCAT attenuation in stable CAD patients with HRP who develop subsequent ACS.

\section{Materials and Methods}

\subsection{Patients}

A cohort of 1254 consecutive patients with available follow-up data, referred for coronary CTA between September 2008 and November 2017, was retrospectively collected. Stable CAD was defined as stable angina with no prior history of CAD. We excluded patients with poor scan quality as assessed by a five-point Likert scale [15] and those who underwent early revascularisation ( $<3$ months). Patients were followed up for longterm outcomes until November 2017. Patients' follow-up was a median of 5.3 years (IQR 5.1 years to 5.7 years). Two independent cardiologists blinded to patient data adjudicated the presence of HRP and ACS. Presence of HRP was determined via visual evaluation of coronary CTA images for HRP characteristics. ACS was defined as per the basis of the third universal definition of myocardial infarction with or without ST elevation (STEMI and NSTEMI, respectively) alongside troponin elevation, and unstable angina, assessed using a combination of medical records, blood results and findings on invasive angiography [16] ACS, late unplanned revascularisation ( $>3$ months from coronary CTA) and cardiac death were study endpoints. Three patients with ACS died from cardiac causes. This study was approved by the Monash Health Human Research Ethics Committee.

\subsection{Coronary CTA Protocol}

Coronary CTA scans were performed using a 320-detector row scanner (Aquilion ONE; Canon Medical Systems Corporation, Otawara, Japan). Acquisitions were obtained during a single breath-hold with prospective ECG triggering, with use of beta-blockers for heart rate control at $60 \mathrm{bpm}$ when required. Coronary CTA acquisition parameters were: detector configuration $320 \times 0.5 \mathrm{~mm}$; tube current $300-500 \mathrm{~mA}$ (depending on body mass index (BMI)); tube potential 100-120 kV; gantry rotation time $275 \mathrm{~ms}$; and temporal resolution $175 \mathrm{~ms}$. Iodinated contrast was administered $(60-90 \mathrm{~mL}, 350 \mathrm{mg}$ iodine per $\mathrm{mL}$ (Omnipaque)) at a rate of $5 \mathrm{~mL} / \mathrm{s}$. Image reconstruction was mediated by the adaptive iterative dose-reduction three-dimensional algorithm (AIDR3D, Canon Medical Systems) and FC43 reconstruction kernel to generate a $512 \times 512$ matrix with $0.5 \mathrm{~mm}$ slice thickness and $0.25 \mathrm{~mm}$ slice increments.

\subsection{Plaque Analysis}

HRP was identified via visual assessment by two independent experts blinded to both patient demographics and clinical data (RM, DW). HRP was defined as the presence of at least two of the following features: positive remodelling (PR), low-attenuation plaque (LAP) or spotty calcification (SC). These features have been defined previously $[4,17]$. Briefly, PR was assessed by comparison of vessel diameter at the coronary lesion to diameter at a reference site proximal to the lesion. This ratio was quantified as a remodelling index (lesion diameter/reference diameter). If the lesion diameter was $\geq 10 \%$ larger than the reference segment, the lesion was defined as positively remodelled. LAP was defined as plaque attenuated at $<30 \mathrm{HU}$. SC was defined on both multiplanar reconstructed images as calcification $<3 \mathrm{~mm}$, and on cross-sectional images as calcification covering $<90^{\circ}$ of the vessel arc. Obstructive CAD was defined on visual assessment as $>50 \%$ diameter stenosis.

Semi-automated software (Vitrea 6 Version 3.0 with SUREPlaque; Vital Images and Canon Medical Systems) was used to quantify total plaque volume, vessel and plaque 
diameter and plaque attenuation. Total plaque burden per lesion was calculated as: (total plaque volume/total vessel volume) $\times 100$. CAD severity was also assessed by segment involvement score (SIS) and segment stenosis score (SSS). SIS refers to the total number of coronary segments with plaque, while SSS refers to the total stenosis score in each segment according to a five-point scale: 0, $0 \%$ stenosis (normal); $1,1-24 \%$ stenosis (minor); 2, 25-49\% stenosis (mild); 3, 50-69\% stenosis (moderate); 4, 70-99\% stenosis (severe) [18,19].

\subsection{PCAT Analysis}

PCAT was quantified in each patient around the proximal right coronary artery $\left(\mathrm{PCAT}_{\mathrm{RCA}}\right)$ and around specific identified lesions ( $\left.\mathrm{PCAT}_{\text {Lesion }}\right)$-culprit coronary lesions in patients with ACS, and the highest-grade stenosis lesions in patients with HRP without ACS and in controls, using semi-automated software (AutoPlaque v2.5, Cedars-Sinai Medical Centre, Los Angeles, CA, USA). Using this software, an experienced operator blinded to clinical data (JY) applied a centreline to the vessel containing the target plaque and demarcated adventitia from surrounding adipose tissue. Adipose tissue was defined as all voxels between $-190 \mathrm{HU}$ and $-30 \mathrm{HU}$ within a predefined volume of interest. This volume of interest included three-dimensional concentric layers extending outward from the operator-traced vessel wall to an extent of $3 \mathrm{~mm}$, the typical diameter of the RCA [11]. PCAT was automatically quantified as the mean attenuation of all voxels within this volume. Analysis excluded all non-adipose tissue and vessel branches not delineated by the manually defined centreline and vessel wall.

PCAT $_{R C A}$ is a standardised technique that provides information on the inflammatory status of the entire coronary tree and is measured in the proximal $10-50 \mathrm{~mm}$ of the RCA, a method which has been validated previously [6-8]. PCAT $_{\text {Lesion }}$ was measured around target lesions, with the proximal and distal borders of the analysis region defined as the proximal and distal ends of the lesion $[6,12,14]$.

\subsection{Statistical Analysis}

The patient selection process is summarised in Figure 1. Of the 1254 patients, 243 patients with HRP were propensity-matched on a 1:1 basis to patients without HRP using a nearest-neighbour approach. Propensity-matching was performed on the basis of age, sex, hypertension, hypercholesterolaemia, diabetes mellitus, current smoking status and family history of ischaemic heart disease (IHD). Patients were excluded on the basis of poor scan quality or the use of dated scan parameters $(n=82,16.9 \%)$. Scan quality was assessed via a five-point Likert score as described previously [15]. Differences in scan parameters within the initial cohort included iterative reconstruction algorithm, reconstruction kernel and the scanner itself. Only scans performed between 2011 and 2016 were included to maintain consistency in scan parameters between patients with HRP and controls. A total of 41 patients with HRP matched to 41 patients without HRP with coronary CTA being performed between 2011 and 2016 were investigated.

Data were tested for normality using the Shapiro-Wilk test. Continuous variables are presented as mean \pm standard deviation or median (interquartile range/IQR), as appropriate. Comparison of continuous variables between groups was assessed using the independent $t$-test. A Chi-square or Fisher's exact test was used for categorical variables. The relationship between PCAT attenuation and age, sex and individual cardiovascular risk factors (hypertension, hypercholesterolaemia, diabetes mellitus, smoking, family history of IHD) was assessed using linear regression. Binary logistic regression was used to assess the relationship between the presence of HRP and PCAT $\mathrm{RCA}_{\text {, correcting }}$ for the aforementioned covariates. Variables with a $p<0.20$ on univariable analyses were included in multivariable models, and a two-sided $p$-value $<0.05$ was considered statistically significant. Additionally, univariable Cox regression analysis was performed to determine the odds of ACS development against covariates found to be significant in logistic regression analysis. The censoring period for this analysis was defined as the date of coronary CTA to the time of ACS, or the date of follow-up in patients who did 
not present with ACS. All statistical analyses were performed using IBM SPSS Statistics (version 25).

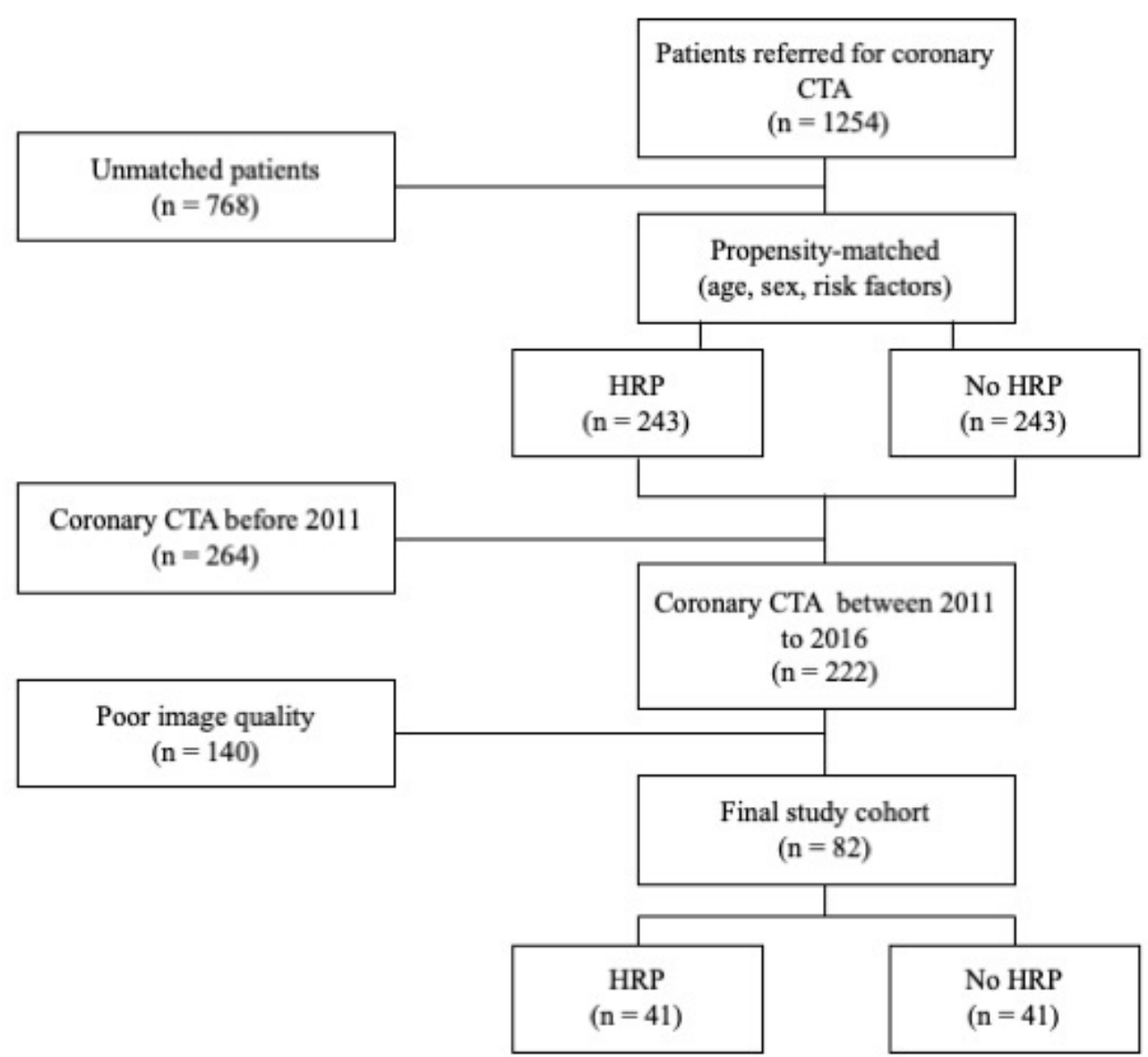

Figure 1. Patient selection and study design. Flow chart depicting selection of final study cohort, including patients with HRP matched to patients without HRP. CTA: computed tomography angiography; HRP: high-risk plaque.

\section{Results}

Baseline patient characteristics are summarised in Table 1 . The final study population comprised 82 patients; mean age was $59.5 \pm 9.7$ years and $67 \%$ were males. Patients with HRP were well-matched to non-HRP patients in terms of age, sex and cardiovascular risk factors. Median time to ACS was 1.9 years (IQR 1.3 years to 4.2 years). ACS was more frequent in patients with HRP compared to controls, but this was not significant $(24.4 \%$ $(n=10)$ vs. $7.3 \%(n=3), p=0.07)$.

\subsection{Plaque and Vessel Characteristics}

All patients with HRP had PR, with a median remodelling index of $1.5(\mathrm{IQR}, 1.31$ to 1.73). Furthermore, LAP was present in $58.5 \%(n=24)$ and SC was present in $53.7 \%(n=22)$ of HRP patients. Obstructive CAD was observed in a small proportion of patients with $\operatorname{HRP}(36.6 \%, n=15)$, and in one control patient $(2.44 \%)$. Compared to patients without HRP, patients with HRP had a higher median SIS (4.5 (IQR 3 to 6) vs. 1.0 (IQR 0 to 4.5), $p<0.001$ ) and SSS (5.5 (IQR 3 to 9.5) vs. 2.0 (IQR 0 to 6 ), $p=0.001$ (Table 1)). 
Table 1. Patient and plaque characteristics.

\begin{tabular}{|c|c|c|c|}
\hline & HRP $(n=41)$ & No HRP $(n=41)$ & $p$-Value \\
\hline \multicolumn{4}{|c|}{ Cardiovascular risk factors } \\
\hline Age, years & $59.8(1.45)$ & $59.2(1.60)$ & 0.77 \\
\hline Male sex & $27(65.9)$ & $27(65.9)$ & 1.0 \\
\hline Hypertension & $16(39.0)$ & $15(36.6)$ & 0.82 \\
\hline Hypercholesterolaemia & $22(53.7)$ & $16(39.0)$ & 0.18 \\
\hline Diabetes mellitus & $6(14.6)$ & $3(7.3)$ & 0.48 \\
\hline Smoker & $7(17.1)$ & $4(9.8)$ & 0.52 \\
\hline Family history of IHD & $22(53.7)$ & $22(53.7)$ & 1.0 \\
\hline Obesity & $3(7.30)$ & $2(4.90)$ & 1.0 \\
\hline ACS & $10(24.4)$ & $3(7.30)$ & 0.07 \\
\hline \multicolumn{4}{|c|}{ Vessel localisation } \\
\hline LAD & $26(63.4)$ & $34(82.9)$ & \\
\hline LCx & $4(9.76)$ & $2(4.88)$ & \\
\hline RCA & $11(26.8)$ & $5(12.2)$ & \\
\hline \multicolumn{4}{|c|}{ Plaque characteristics } \\
\hline PR & $41(100)$ & - & \\
\hline LAP & $24(58.5)$ & - & \\
\hline $\mathrm{SC}$ & $22(53.7)$ & - & \\
\hline Remodelling index * & $1.5(1.31,1.73)$ & - & \\
\hline Obstructive CAD & $15(36.6)$ & $1(2.44)$ & $<0.001$ \\
\hline Total plaque volume & $55.6(6.93)$ & - & \\
\hline Total plaque burden & $152(64.6)$ & - & \\
\hline \multicolumn{4}{|c|}{ CCTA segment scores * } \\
\hline Segment involvement score & $4.5(3,6)$ & $1.0(0,4.5)$ & $<0.001$ \\
\hline Segment stenosis score & $5.5(3,9.5)$ & $2.0(0,6)$ & 0.001 \\
\hline
\end{tabular}

\subsection{Relationship between PCAT and HRP}

PCAT $_{\text {RCA }}$ was significantly higher in patients with HRP compared to patients without $\operatorname{HRP}\left(-80.7 \pm 6.5 \mathrm{HU}\right.$ vs. $-84.2 \pm 8.1 \mathrm{HU}, p=0.03$ (Figure 2)). PCAT $_{\text {Lesion }}$ was also higher in HRP lesions compared to the highest-grade stenosis lesions in controls $(-79.6 \pm 7.9 \mathrm{HU}$ vs. $-84.2 \pm 10.3 \mathrm{HU}, p=0.04)$. PCAT $\mathrm{RCA}_{\text {was }}$ correlated with $\mathrm{PCAT}_{\text {Lesion }}(\mathrm{r}=0.513$, $p<0.01$ ), but there was no significant difference in PCAT $_{\text {RCA }}$ and PCAT $_{\text {Lesion }}$ within patients $(-81.4 \pm 6.8 \mathrm{HU}$ vs. $-81.4 \pm 9.1 \mathrm{HU}, p=0.98)$. A visual representation of PCAT attenuation in a patient with HRP and a control patient is shown in Figure 3.

\subsection{Relationship between PCAT and ACS}

PCAT $_{\text {RCA }}$ was higher in patients presenting with subsequent ACS compared to those without subsequent ACS ( $-78.03 \mathrm{HU} \pm 7.32$ vs. $-83.3 \mathrm{HU} \pm 7.29, p=0.02)$. PCAT $_{\text {Lesion }}$ was only numerically higher in patients presenting with subsequent ACS compared to those who did not present with ACS $(-77.3 \mathrm{HU} \pm 8.82$ vs. $-82.4 \mathrm{HU} \pm 8.93, p=0.07)$.

PCAT $_{\text {RCA }}$ was higher in HRP patients presenting with ACS than HRP patients who did not present with subsequent ACS $(-76.8 \mathrm{HU} \pm 5.69$ vs. $-82.0 \mathrm{HU} \pm 6.32, p=0.03$ (Figure 2)). $\mathrm{PCAT}_{\text {Lesion }}$ was only numerically higher in patients with HRP who presented with ACS $(-76.8 \mathrm{HU} \pm 9.44$ vs. $-80.5 \mathrm{HU} \pm 7.22, p=0.2)$.

\subsection{Sex-Specific Differences in PCAT}

Among all patients, both PCAT $_{\mathrm{RCA}}$ and $\mathrm{PCAT}_{\text {Lesion }}$ were significantly higher in men than in women (PCAT RCA $:-80.5 \pm 7.03 \mathrm{HU}$ vs. $-86.1 \pm 7.08 \mathrm{HU}, p<0.001 ; \mathrm{PCAT}_{\text {Lesion: }}$ : $-79.6 \pm 9.06 \mathrm{HU}$ vs. $-85.2 \pm 7.96 \mathrm{HU}, p=0.02$ (Figure 4 )). Similar results were observed among patients with $\mathrm{HRP}\left(\mathrm{PCAT}_{\mathrm{RCA}}:-78.6 \pm 5.97 \mathrm{HU}\right.$ vs. $-84.8 \pm 5.58 \mathrm{HU}, p=0.002$; $\mathrm{PCAT}_{\text {Lesion }}:-77.7 \pm 7.43 \mathrm{HU}$ vs. $-83.4 \pm 7.52 \mathrm{HU}, p=0.03$ (Figure 4 )). 


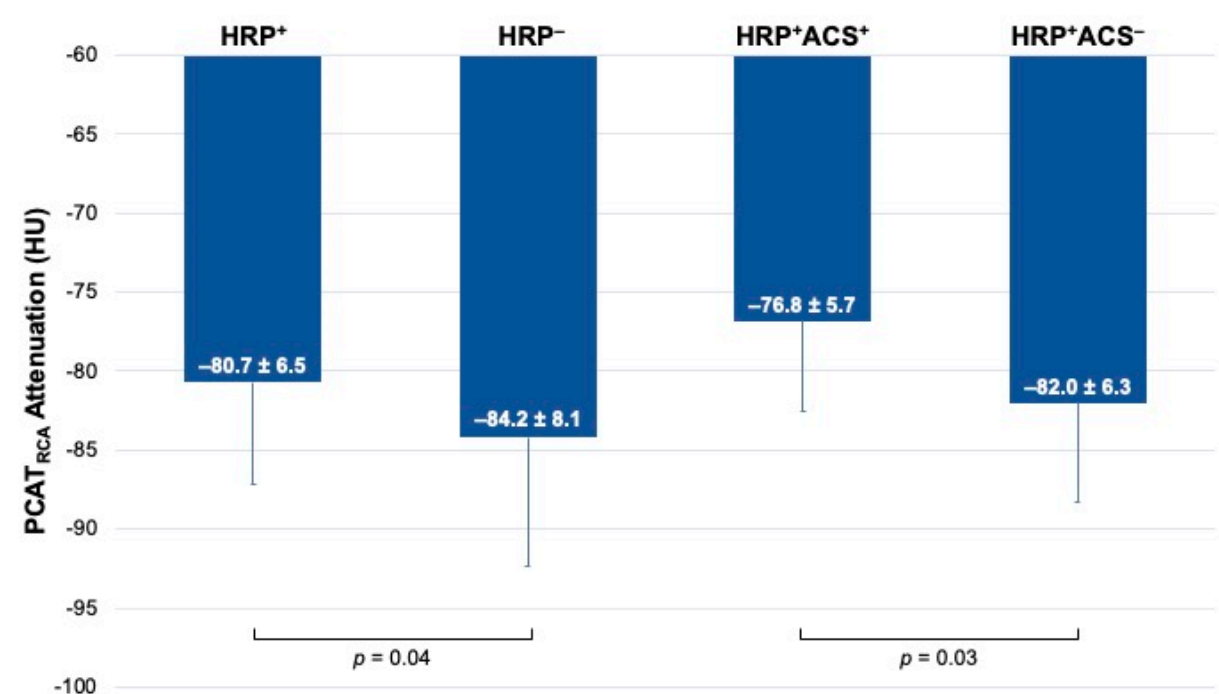

Figure 2. $\mathrm{PCAT}_{\mathrm{RCA}}$ attenuation by presence of HRP and subsequent presentation with ACS. Bar graphs of per-patient differences in PCAT attenuation in patients with $\mathrm{HRP}\left(\mathrm{HRP}^{+}\right)$and without $\mathrm{HRP}\left(\mathrm{HRP}^{-}\right)$, and in patients with HRP who developed ACS $\left(\mathrm{HRP}^{+} \mathrm{ACS}^{+}\right)$and patients with $\mathrm{HRP}$ who did not develop ACS $\left(\mathrm{HRP}^{+} \mathrm{ACS}^{-}\right)$. ACS: acute coronary syndrome.
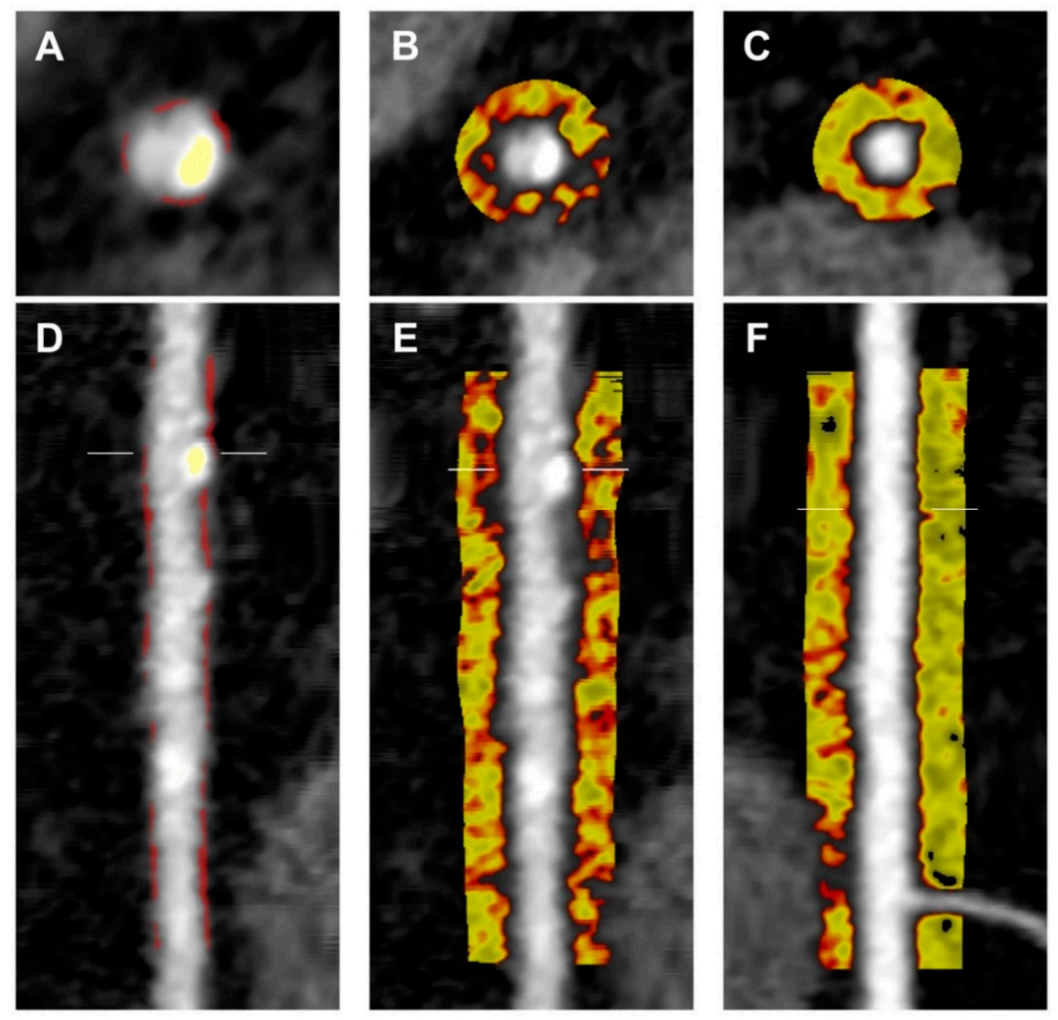

Figure 3. Case comparison of per-patient PCAT quantification. Comparison of the RCA of a patient with HRP versus a patient without HRP (control) as shown on coronary CTA. RCA in patient with HRP shown in cross-sectional (A) and longitudinal (D) views, with calcified plaque (yellow) and non-calcified plaque (red) highlighted. Representation of PCAT attenuation of patient with HRP $(-75.6 \mathrm{HU})$ and control (-93.9 HU) shown in cross-sectional $(\mathbf{B}, \mathbf{C})$ and longitudinal $(\mathbf{E}, \mathbf{F})$ views. Colour map corresponds to CT attenuation in Hounsfield Units (HU) ranging from $-190 \mathrm{HU}$ (yellow) to $-30 \mathrm{HU}$ (red). Cross-sectional view in patient with HRP shown in panel (B) versus control shown in panel (C). Longitudinal view in patient with HRP shown in panel (E) versus control shown in panel (F). RCA: right coronary artery. 


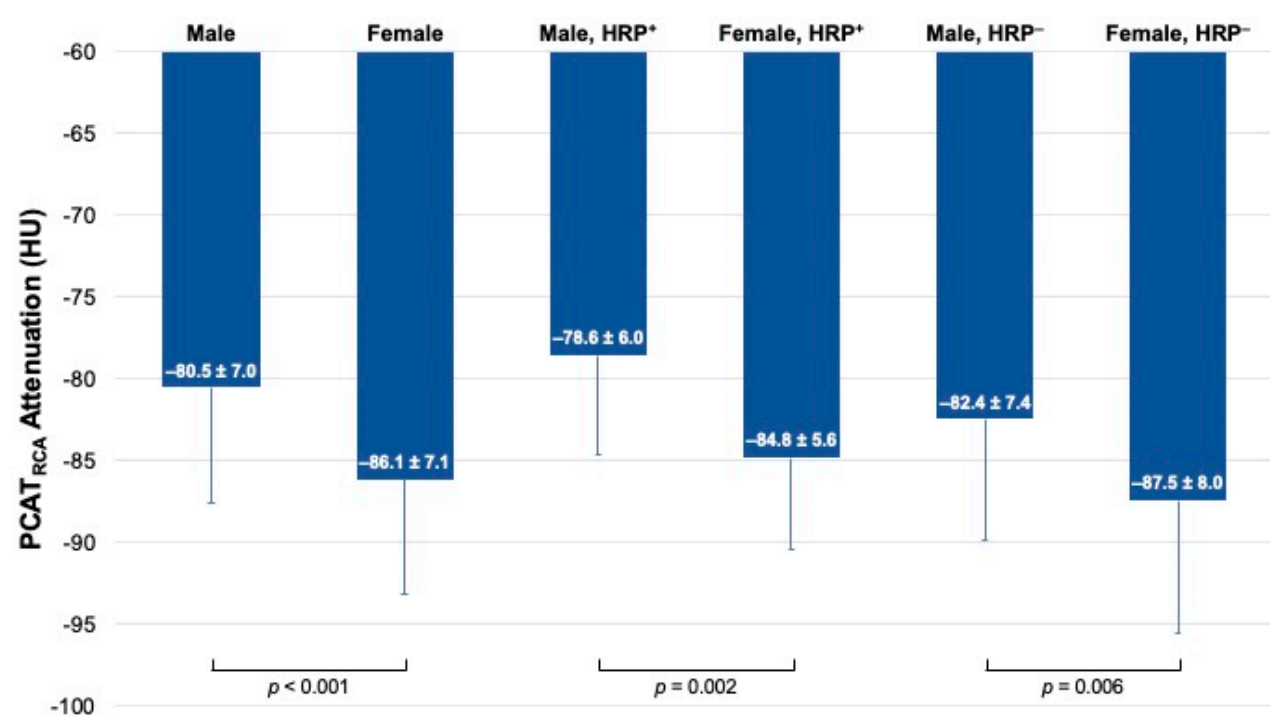

Figure 4. $\mathrm{PCAT}_{\mathrm{RCA}}$ attenuation by gender and presence of HRP. Bar graphs of per-patient differences in PCAT attenuation in men (Male) and women (Female), men with HRP (Male, $\mathrm{HRP}^{+}$) and women with HRP (Female, $\mathrm{HRP}^{+}$), and men without HRP (Male, $\mathrm{HRP}^{-}$) and women without HRP (Female, $\mathrm{HRP}^{-}$). ACS: acute coronary syndrome.

\subsection{Multivariable Regression Analysis}

On multivariable linear regression analysis, sex, HRP and current smoking status were

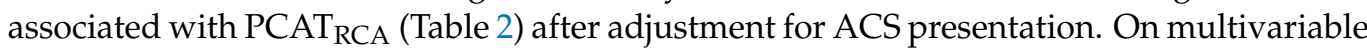
logistic regression, $\mathrm{PCAT}_{\mathrm{RCA}}$ was independently associated with the presence of HRP (Table 3).

Table 2. Univariable and multivariable linear regression analyses of covariates and PCAT $\mathrm{RCA}_{\text {. }}$

\begin{tabular}{|c|c|c|c|c|c|c|}
\hline \multirow[b]{2}{*}{ Variable } & \multicolumn{3}{|c|}{ Univariable } & \multicolumn{3}{|c|}{ Multivariable } \\
\hline & Beta & $95 \% \mathrm{CI}$ & $p$-value & Beta & $95 \% \mathrm{CI}$ & $p$-value \\
\hline Age & -0.032 & $-0.204,0.140$ & 0.712 & & & \\
\hline Male sex & 5.631 & $2.367,8.895$ & 0.001 & 5.085 & $1.986,8.814$ & 0.002 \\
\hline Presence of HRP & 3.437 & $0.210,6.663$ & 0.037 & 3.017 & $0.087,5.947$ & 0.044 \\
\hline Presentation with ACS & 5.238 & $0.851,9.626$ & 0.020 & 0.156 & $-0.970,7.338$ & 0.131 \\
\hline Hypertension & 0.469 & $-2.948,3.887$ & 0.785 & & & \\
\hline Hypercholesterolaemia & 1.232 & $-2.082,4.545$ & 0.462 & & & \\
\hline Diabetes & -0.174 & $-5.478,5.130$ & 0.948 & & & \\
\hline Smoker & 7.146 & $2.548,11.744$ & 0.003 & 5.733 & $1.396,10.070$ & 0.010 \\
\hline Family history of IHD & 1.366 & $-1.945,4.677$ & 0.414 & & & \\
\hline Obesity & -2.505 & $-9.412,4.401$ & 0.472 & & & \\
\hline
\end{tabular}

Table 3. Univariable and multivariable logistic regression analyses of covariates and HRP.

\begin{tabular}{|c|c|c|c|c|c|c|}
\hline \multirow[b]{2}{*}{ Variable } & \multicolumn{3}{|c|}{ Univariable } & \multicolumn{3}{|c|}{ Multivariable } \\
\hline & OR & $95 \% \mathrm{CI}$ & $p$-value & OR & $95 \% \mathrm{CI}$ & $p$-value \\
\hline Age & 1.007 & $0.963,1.053$ & 0.766 & & & \\
\hline Male sex & 1.0 & $0.401,2.491$ & 1.0 & & & \\
\hline $\mathrm{PCAT}_{\mathrm{RCA}}$ & 1.066 & $1.003,1.134$ & 0.041 & 1.064 & $1.000,1.132$ & 0.049 \\
\hline Hypertension & 1.109 & $0.454,2.710$ & 0.820 & & & \\
\hline Hypercholesterolaemia & 1.809 & $0.752,4.352$ & 0.186 & 1.723 & $0.701,4.238$ & 0.236 \\
\hline Diabetes & 2.171 & $0.504,9.350$ & 0.298 & & & \\
\hline Smoker & 1.904 & $0.512,7.085$ & 0.337 & & & \\
\hline Family history of IHD & 1.0 & $0.420,2.382$ & 1.0 & & & \\
\hline Obesity & 1.539 & $0.243,9.733$ & 0.647 & & & \\
\hline
\end{tabular}




\subsection{Time-Dependent Analysis}

On univariable Cox regression analysis, ACS was significantly associated with HRP presence (OR $=3.79$ (95\%CI 1.04 to 13.85), $p=0.04$ ) and PCAT $_{\mathrm{RCA}}(\mathrm{OR}=1.09(95 \% \mathrm{CI} 1.01$ to $1.18), p=0.03)$, but not with gender ( $\mathrm{OR}=3.79(95 \% \mathrm{CI} 0.36$ to 3.86$), p=0.78)$. Additionally, ACS was significantly associated with SSS (OR $=1.12(95 \% \mathrm{CI} 1.01,1.24), p=0.04)$ and the presence of obstructive CAD (OR $=4.80(95 \% \mathrm{CI} 1.60,14.40), p<0.01)$, but not by SIS $(p=0.27)$. No traditional cardiovascular risk factors were significantly associated with ACS (all $p>0.1$ ).

On Kaplan-Meier analysis, patients with HRP harboured significantly greater risk of ACS than patients without HRP (log-rank $p=0.03$ (Figure 5)). Patients were also stratified into high- and low-PCAT ${ }_{\mathrm{RCA}}$ subgroups around a cutoff of the mean $\mathrm{PCAT}_{\mathrm{RCA}}$ within the entire cohort $(-82.4 \mathrm{HU} \pm 7.50)$. While patients with high-PCAT $\mathrm{RCA}_{\mathrm{RA}}$ experienced lower percentage survival, this did not achieve significance $(\log$-rank $p=0.08)$.

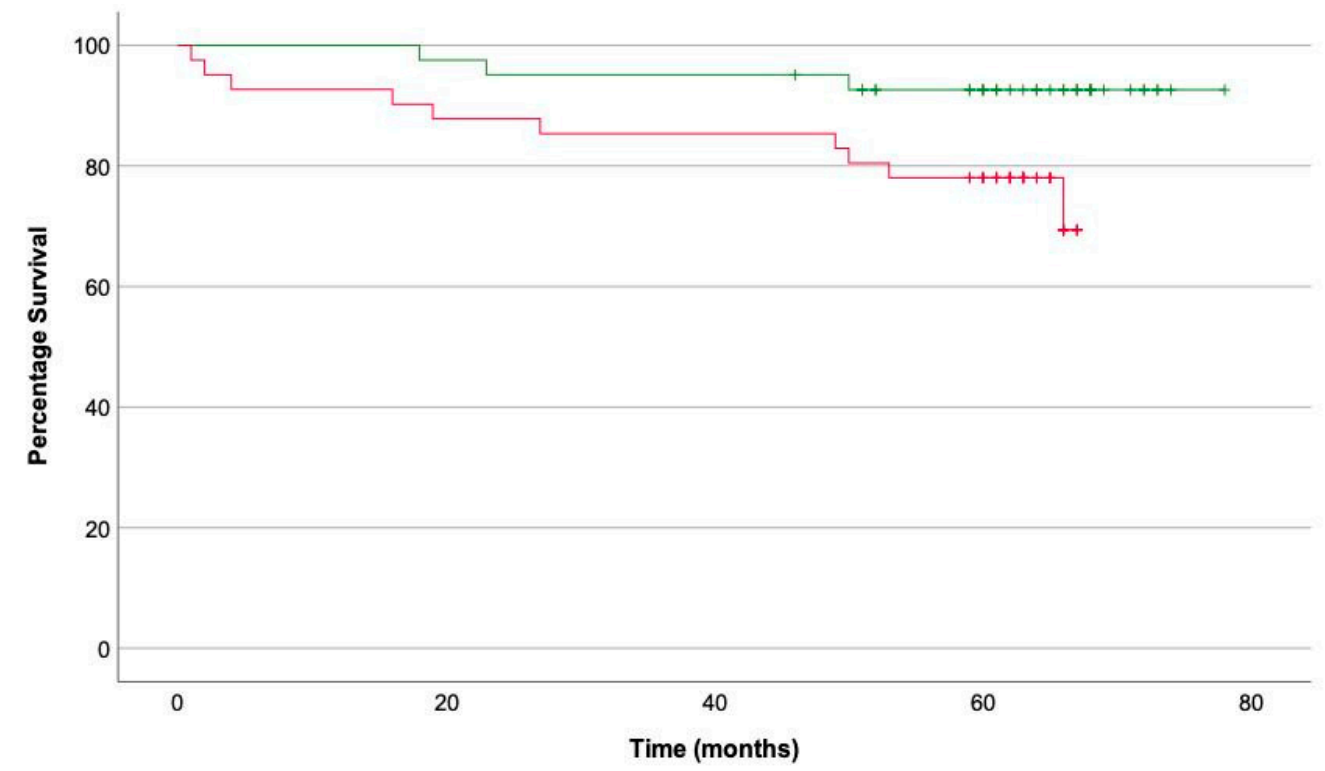

Figure 5. Survival curve of patients with HRP (red) versus patients without HRP (green).

\section{Discussion}

Our study evaluated the association between PCAT attenuation and ACS in patients

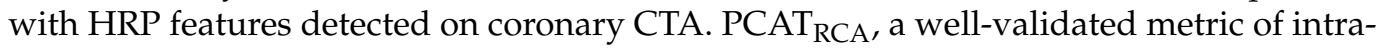
coronary inflammation, is increased in HRP-positive patients who go on to develop ACS compared to those who do not develop major coronary events. Furthermore, HRP presence and PCAT $\mathrm{RCA}_{\mathrm{B}}$ is associated with an increased rate of ACS. In addition, we also report sex-specific differences in PCAT attenuation, with increased attenuation being observed in men with HRP compared to women with HRP. The findings of this study highlight differentials in coronary inflammation in the context of ACS, particularly among a patient population at a greater risk of developing events.

The relationship between inflammation and vulnerable atherosclerotic plaque is welldocumented in the literature $[2,20,21]$. Observational studies have established a robust association between HRP and ACS $[4,5,17]$. Recent evidence arising from the SCOTHEART study [22] demonstrates the strong predictive value of LAP for fatal and nonfatal myocardial infarction (MI) in a large study population. Moreover, patients within this cohort with the combination of both nonobstructive CAD and LAP burden $>4 \%$ harboured a sixfold increased risk of MI, highlighting that vulnerable plaque morphology plays a critical role in the development of coronary events independent of plaque-related stenosis.

PCAT studies show that both pan-coronary and lesion-specific inflammation are associated with high-risk lesions in stable CAD [8,14], as well as major coronary events [7,12], 
indicating potential for PCAT attenuation to detect incipient CAD before the appearance of vulnerable plaque. We report that both HRP presence and PCAT $_{R C A}$ were significantly associated with ACS development. Moreover, $\mathrm{PCAT}_{R C A}$ was higher in patients with HRP who then went on to develop ACS. A number of prior studies have evaluated the relationship between coronary inflammation and ACS in either per-patient [7] or per-lesion forms of PCAT assessment [12,14]. In per-patient analysis, Oikonomou et al. found that increased PCAT $_{\text {RCA }}$ was predictive of MI in patients with stable CAD [7]. Likewise, Lin et al. found that per-patient PCAT attenuation was associated with AMI and was distinctly higher in these patients compared to stable CAD or control patients [10]. Studies evaluating perlesion analysis demonstrated increased attenuation around culprit lesions in ACS [12,23] and MI [6,24]. Importantly, Gaibazzi et al. described increased per-vessel PCAT attenuation and HRP characteristics in patients with myocardial infarction with non-obstructive coronary artery disease (MINOCA) and Tako-Tsubo Syndrome (TTS) [24]. The largely non-obstructive nature of vulnerable plaque observed in our study is also evident in the literature $[1,2,21,22]$ and further evidences that HRP features and plaque-specific inflammation may be additive to luminal stenosis in predicting event risk. Indeed, increased PCAT attenuation results in an increased prospective risk of cardiac mortality, among both patients with and without HRP [25]. Nevertheless, we found that only PCAT RCA $_{\text {and not }}$ PCAT $_{\text {Lesion }}$ were associated with ACS, though both metrics were correlated with one another. A possible explanation may reside in the significant range observed in the duration from coronary CTA to presentation with ACS in these patients; in some cases, $\mathrm{PCAT}_{\text {Lesion }}$ may have therefore reflected only a limited degree of inflammation surrounding plaques well before their development into culprit lesions. It is plausible that HRP may represent a series of structural changes appearing later in the inflammatory process which are more acutely related to vulnerability, as a number of studies demonstrate that HRP phenotypes associate with ACS occurring within a year of follow-up [4,26]. Moreover, PCAT Lesion $_{\text {n }}$ captures rapid changes in coronary inflammation that occur within weeks of MI [6], further underscoring the dynamic nature of plaque-specific inflammation. In contrast, increased PCAT $_{R C A}$ demonstrates a level of inflammation throughout the coronary vasculature that may be present long before localisation to specific sites and culminates in HRP formation. Further studies investigating per-patient and per-lesion forms of PCAT assessment and ACS are required to fully elucidate the inflammatory changes occurring globally within the coronary vasculature and specific to culprit lesions.

We also report significantly increased $\mathrm{PCAT}_{\mathrm{RCA}}$ and $\mathrm{PCAT}_{\text {Lesion }}$ in men overall and specifically within groups with HRP. Increased vascular inflammation has been observed in men by means of elevated serum inflammatory biomarkers [27], but sex-specific differences in coronary inflammation remain unclear. Recent studies report increased PCAT attenuation in men compared to women $[9,28]$, and the magnitude of HU difference in these studies was similar to our own findings, although we did not adjust for the influence of age or technical parameters. To the best of our knowledge, ours is the first study that reports increased coronary inflammation shown by both PCAT $_{R C A}$ and PCAT $_{\text {Lesion }}$ specifically in men with HRP. As stated previously, the association between HRP and cardiac events is well-documented in the literature [5], but the impact of sex on this association remains uncertain. In a propensity-matched study, Plank et al. found that men had a higher proportion of HRP features and MACE, but the presence of mixed plaque and non-calcified plaque was significantly more prevalent among women [29]. Importantly, numerous studies postulate that middle-aged women may indeed face a higher risk of MACE compared to men when obstructive CAD or HRP is present [29,30], while others demonstrate higher incidence of ACS among men despite a similar prevalence of HRP [31]. While it is clear that sex-specific differences may exist in plaque morphology, elucidating potential differentials in coronary inflammation in the context of vulnerable coronary disease may offer a level of clarity in this area and indicate if there is indeed a heightened risk of major coronary events faced by either sex. The low number of events in our study limited the capacity to further stratify associations between PCAT attenuation and ACS by sex. However, the finding of increased 


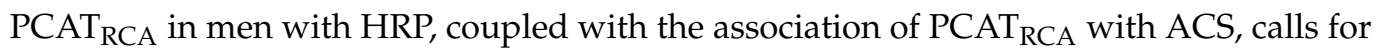
further investigation into this area to explore the potentially disproportionate risk of major coronary events that men may face with or without HRP.

As atherosclerosis is recognised as a disease of chronic inflammation, the advent of PCAT attenuation as an indirect metric of coronary inflammation provides a useful diagnostic and prognostic tool in evaluating inflammatory risk. This study examines current forms of PCAT assessment in the context of stable CAD patients with HRP, finding that PCAT attenuation is able to detect not only the presence of HRP but the subsequent development of ACS. PCAT therein possesses diagnostic value, enabling indirect assessment of inflammatory risk in individuals with suspected CAD. Incorporation of PCAT assessment into coronary CTA-based risk stratification has been espoused previously [7], and may enhance primary prevention and potential delineation of inflammatory risk prior to plaque formation. Moreover, higher degrees of coronary inflammation shown by increased PCAT would allow for timelier and proactive clinical intervention.

While these findings are novel, this was a small, retrospective, single-centre study. This consequentially limited the number of patients with ACS studied in this cohort, which may

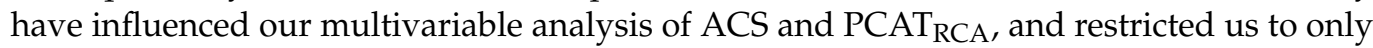
univariable time-dependent analysis of these variables. Development of ACS in patients with CAD would be best studied by large longitudinal studies, though we do report increased PCAT RCA even among a small proportion of ACS cases. We performed both $\mathrm{PCAT}_{\mathrm{RCA}}$ and $\mathrm{PCAT}_{\text {Lesion }}$ assessment, but the latter may be hampered by factors pertaining to luminal attenuation in the left anterior descending and left circumflex arteries, which decline alongside decreases in luminal diameter and contrast enhancement from ostial to distal segments [32]. Moreover, partial volume averaging due to the spatial resolution limitations of coronary CTA may affect attenuation measurements in pericoronary fat. Finally, data on medical therapy, such as statins and antiplatelet therapy, were not collected for this cohort and were therefore not included in adjusted analyses.

\section{Conclusions}

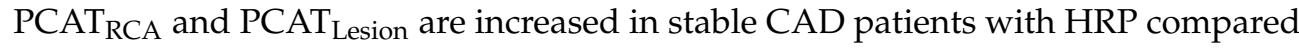

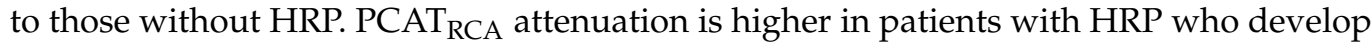
ACS and predicts ACS in conjunction with the presence of HRP. PCAT attenuation is higher in men compared to women with HRP. This non-invasive imaging biomarker may identify patients at greater risk of future events, but clinical application of these measures requires further investigation.

Author Contributions: Conceptualization and methodology, R.K.M. and D.T.L.W.; software and validation, A.L. and D.D.; formal analysis and manuscript preparation, J.Y.; manuscript review and editing, A.L., N.N., J.D.C., S.J.N. and D.T.L.W.; project administration, J.D.C. and S.J.N.; supervision, N.N., S.J.N. and D.T.L.W. All authors have read and agreed to the published version of the manuscript.

Funding: This research received no external funding.

Institutional Review Board Statement: The study was conducted according to the guidelines of the Declaration of Helsinki and approved by the Human Research Ethics Committee of Monash.

Informed Consent Statement: Informed consent was obtained from all subjects involved in the study.

Data Availability Statement: No new data were created or analysed in this study. Data sharing is not applicable to this article.

Conflicts of Interest: The authors declare no conflict of interest.

\section{References}

1. Fishbein, M.C.; Siegel, R.J. How big are coronary atherosclerotic plaques that rupture? Circulation 1996, 94, 2662-2666. [CrossRef]

2. Virmani, R.; Kolodgie, F.D.; Burke, A.P.; Farb, A.; Schwartz, S.M. Lessons from sudden coronary death: A comprehensive morphological classification scheme for atherosclerotic lesions. Arterioscler. Thromb. Vasc. Biol. 2000, 20, 1262-1275. [CrossRef] [PubMed] 
3. Motoyama, S.; Kondo, T.; Sarai, M.; Sugiura, A.; Harigaya, H.; Sato, T.; Inoue, K.; Okumura, M.; Ishii, J.; Anno, H.; et al. Multislice computed tomographic characteristics of coronary lesions in acute coronary syndromes. J. Am. Coll. Cardiol. 2007, 50, 319-326. [CrossRef] [PubMed]

4. Motoyama, S.; Sarai, M.; Harigaya, H.; Anno, H.; Inoue, K.; Hara, T.; Naruse, H.; Ishii, J.; Hishida, H.; Wong, N.D.; et al. Computed tomographic angiography characteristics of atherosclerotic plaques subsequently resulting in acute coronary syndrome. $J$. Am. Coll. Cardiol. 2009, 54, 49-57. [CrossRef] [PubMed]

5. Nerlekar, N.; Ha, F.J.; Cheshire, C.; Rashid, H.; Cameron, J.D.; Wong, D.T.; Seneviratne, S.; Brown, A.J. Computed Tomographic Coronary Angiography-Derived Plaque Characteristics Predict Major Adverse Cardiovascular Events: A Systematic Review and Meta-Analysis. Circ. Cardiovasc. Imaging 2018, 11, e006973. [CrossRef] [PubMed]

6. Antonopoulos, A.S.; Sanna, F.; Sabharwal, N.; Thomas, S.; Oikonomou, E.K.; Herdman, L.; Margaritis, M.; Shirodaria, C.; Kampoli, A.M.; Akoumianakis, I.; et al. Detecting human coronary inflammation by imaging perivascular fat. Sci. Transl. Med. 2017, 9. [CrossRef] [PubMed]

7. Oikonomou, E.K.; Marwan, M.; Desai, M.Y.; Mancio, J.; Alashi, A.; Hutt Centeno, E.; Thomas, S.; Herdman, L.; Kotanidis, C.P.; Thomas, K.E.; et al. Non-invasive detection of coronary inflammation using computed tomography and prediction of residual cardiovascular risk (the CRISP CT study): A post-hoc analysis of prospective outcome data. Lancet 2018, 392, 929-939. [CrossRef]

8. Goeller, M.; Tamarappoo, B.K.; Kwan, A.C.; Cadet, S.; Commandeur, F.; Razipour, A.; Slomka, P.J.; Gransar, H.; Chen, X.; Otaki, Y.; et al. Relationship between changes in pericoronary adipose tissue attenuation and coronary plaque burden quantified from coronary computed tomography angiography. Eur. Heart J. Cardiovasc. Imaging 2019. [CrossRef]

9. Goeller, M.; Rahman Ihdayhid, A.; Cadet, S.; Lin, A.; Adams, D.; Thakur, U.; Yap, G.; Marwan, M.; Achenbach, S.; Dey, D.; et al. Pericoronary adipose tissue and quantitative global non-calcified plaque characteristics from CT angiography do not differ in matched South Asian, East Asian and European-origin Caucasian patients with stable chest pain. Eur. J. Radiol. 2020, 125, 108874. [CrossRef]

10. Lin, A.; Nerlekar, N.; Yuvaraj, J.; Fernandes, K.; Jiang, C.; Dey, D.; Nicholls, S.J.; Wong, D.T.L. Pericoronary Adipose Tissue Computed Tomography Attenuation in Different Stages of Coronary Artery Disease: A Cross-Sectional Study. J. Am. Coll. Cardiol. 2020, 75, 1718. [CrossRef]

11. Lin, A.; Nerlekar, N.; Munnur, R.K.; Kataoka, Y.; Andrews, J.; Dey, D.; Nicholls, S.J.; Wong, D.T.L. Cholesterol crystal-induced coronary inflammation: Insights from optical coherence tomography and pericoronary adipose tissue computed tomography attenuation. J. Cardiovasc. Comput. Tomogr. 2020, 14, 277-278. [CrossRef]

12. Goeller, M.; Achenbach, S.; Cadet, S.; Kwan, A.C.; Commandeur, F.; Slomka, P.J.; Gransar, H.; Albrecht, M.H.; Tamarappoo, B.K.; Berman, D.S.; et al. Pericoronary Adipose Tissue Computed Tomography Attenuation and High-Risk Plaque Characteristics in Acute Coronary Syndrome Compared With Stable Coronary Artery Disease. JAMA Cardiol. 2018, 3, 858-863. [CrossRef] [PubMed]

13. Marwan, M.; Hell, M.; Schuhback, A.; Gauss, S.; Bittner, D.; Pflederer, T.; Achenbach, S. CT Attenuation of Pericoronary Adipose Tissue in Normal Versus Atherosclerotic Coronary Segments as Defined by Intravascular Ultrasound. J. Comput. Assist. Tomogr. 2017, 41, 762-767. [CrossRef] [PubMed]

14. Kwiecinski, J.; Dey, D.; Cadet, S.; Lee, S.E.; Otaki, Y.; Huynh, P.T.; Doris, M.K.; Eisenberg, E.; Yun, M.; Jansen, M.A.; et al. Peri-Coronary Adipose Tissue Density Is Associated With (18)F-Sodium Fluoride Coronary Uptake in Stable Patients with High-Risk Plaques. JACC Cardiovasc. Imaging 2019, 12, 2000-2010. [CrossRef]

15. Wong, D.T.L.; Soh, S.Y.; Ko, B.S.; Cameron, J.D.; Crossett, M.; Nasis, A.; Troupis, J.; Meredith, I.T.; Seneviratne, S.K. Superior CT coronary angiography image quality at lower radiation exposure with second generation 320-detector row CT in patients with elevated heart rate: A comparison with first generation 320-detector row CT. Cardiovasc. Diagn. Ther. 2014, 4, 299-306. [CrossRef] [PubMed]

16. Thygesen, K.; Alpert, J.S.; Jaffe, A.S.; Simoons, M.L.; Chaitman, B.R.; White, H.D.; Writing Group on behalf of the Joint ESC/ACCF/AHA/WHF. Task Force for the Universal Definition of Myocardial Infarction. Third universal definition of myocardial infarction. Glob. Heart 2012, 7, 275-295. [CrossRef] [PubMed]

17. Motoyama, S.; Ito, H.; Sarai, M.; Kondo, T.; Kawai, H.; Nagahara, Y.; Harigaya, H.; Kan, S.; Anno, H.; Takahashi, H.; et al. Plaque Characterization by Coronary Computed Tomography Angiography and the Likelihood of Acute Coronary Events in Mid-Term Follow-Up. J. Am. Coll. Cardiol. 2015, 66, 337-346. [CrossRef]

18. Min, J.K.; Shaw, L.J.; Devereux, R.B.; Okin, P.M.; Weinsaft, J.W.; Russo, D.J.; Lippolis, N.J.; Berman, D.S.; Callister, T.Q. Prognostic value of multidetector coronary computed tomographic angiography for prediction of all-cause mortality. J. Am. Coll. Cardiol. 2007, 50, 1161-1170. [CrossRef] [PubMed]

19. Kolossvary, M.; Szilveszter, B.; Edes, I.F.; Nardai, S.; Voros, V.; Hartyanszky, I.; Merkely, B.; Voros, S.; Maurovich-Horvat, P. Comparison of Quantity of Coronary Atherosclerotic Plaques Detected by Computed Tomography Versus Angiography. Am. J. Cardiol. 2016, 117, 1863-1867. [CrossRef] [PubMed]

20. van der Wal, A.C.; Becker, A.E.; van der Loos, C.M.; Das, P.K. Site of intimal rupture or erosion of thrombosed coronary atherosclerotic plaques is characterized by an inflammatory process irrespective of the dominant plaque morphology. Circulation 1994, 89, 36-44. [CrossRef] [PubMed]

21. Kolodgie, F.D.; Virmani, R.; Burke, A.P.; Farb, A.; Weber, D.K.; Kutys, R.; Finn, A.V.; Gold, H.K. Pathologic assessment of the vulnerable human coronary plaque. Heart 2004, 90, 1385-1391. [CrossRef] 
22. Williams, M.C.; Kwiecinski, J.; Doris, M.; McElhinney, P.; D’Souza, M.S.; Cadet, S.; Adamson, P.D.; Moss, A.J.; Alam, S.; Hunter, A.; et al. Low-Attenuation Noncalcified Plaque on Coronary Computed Tomography Angiography Predicts Myocardial Infarction: Results From the Multicenter SCOT-HEART Trial (Scottish Computed Tomography of the HEART). Circulation 2020, 141, 1452-1462. [CrossRef] [PubMed]

23. Hedgire, S.; Baliyan, V.; Zucker, E.J.; Bittner, D.O.; Staziaki, P.V.; Takx, R.A.P.; Scholtz, J.E.; Meyersohn, N.; Hoffmann, U.; Ghoshhajra, B. Perivascular Epicardial Fat Stranding at Coronary CT Angiography: A Marker of Acute Plaque Rupture and Spontaneous Coronary Artery Dissection. Radiology 2018, 287, 808-815. [CrossRef]

24. Gaibazzi, N.; Martini, C.; Botti, A.; Pinazzi, A.; Bottazzi, B.; Palumbo, A.A. Coronary Inflammation by Computed Tomography Pericoronary Fat Attenuation in MINOCA and Tako-Tsubo Syndrome. J. Am. Heart Assoc. 2019, 8, e013235. [CrossRef]

25. Oikonomou, E.K.; Desai, M.Y.; Marwan, M.; Kotanidis, C.P.; Antonopoulos, A.S.; Schottlander, D.; Channon, K.M.; Neubauer, S.; Achenbach, S.; Antoniades, C. Perivascular Fat Attenuation Index Stratifies Cardiac Risk Associated With High-Risk Plaques in the CRISP-CT Study. J. Am. Coll. Cardiol. 2020, 76, 755-757. [CrossRef] [PubMed]

26. Schuurman, A.S.; Vroegindewey, M.M.; Kardys, I.; Oemrawsingh, R.M.; Garcia-Garcia, H.M.; van Geuns, R.J.; Regar, E.; Van Mieghem, N.M.; Ligthart, J.; Serruys, P.W.; et al. Prognostic Value of Intravascular Ultrasound in Patients With Coronary Artery Disease. J. Am. Coll. Cardiol. 2018, 72, 2003-2011. [CrossRef]

27. Kaptoge, S.; Seshasai, S.R.; Gao, P.; Freitag, D.F.; Butterworth, A.S.; Borglykke, A.; Di Angelantonio, E.; Gudnason, V.; Rumley, A.; Lowe, G.D.; et al. Inflammatory cytokines and risk of coronary heart disease: New prospective study and updated meta-analysis. Eur. Heart J. 2014, 35, 578-589. [CrossRef] [PubMed]

28. Sugiyama, T.; Kanaji, Y.; Hoshino, M.; Yamaguchi, M.; Hada, M.; Ohya, H.; Sumino, Y.; Hirano, H.; Kanno, Y.; Horie, T.; et al. Determinants of Pericoronary Adipose Tissue Attenuation on Computed Tomography Angiography in Coronary Artery Disease. J. Am. Heart Assoc. 2020, 9, e016202. [CrossRef] [PubMed]

29. Plank, F.; Beyer, C.; Friedrich, G.; Wildauer, M.; Feuchtner, G. Sex differences in coronary artery plaque composition detected by coronary computed tomography: Quantitative and qualitative analysis. Neth. Heart J. 2019, 27, 272-280. [CrossRef]

30. Ferencik, M.; Mayrhofer, T.; Bittner, D.O.; Emami, H.; Puchner, S.B.; Lu, M.T.; Meyersohn, N.M.; Ivanov, A.V.; Adami, E.C.; Patel, M.R.; et al. Use of High-Risk Coronary Atherosclerotic Plaque Detection for Risk Stratification of Patients With Stable Chest Pain: A Secondary Analysis of the PROMISE Randomized Clinical Trial. JAMA Cardiol. 2018, 3, 144-152. [CrossRef]

31. Lansky, A.J.; Ng, V.G.; Maehara, A.; Weisz, G.; Lerman, A.; Mintz, G.S.; De Bruyne, B.; Farhat, N.; Niess, G.; Jankovic, I.; et al. Gender and the extent of coronary atherosclerosis, plaque composition, and clinical outcomes in acute coronary syndromes. JACC Cardiovasc. Imaging 2012, 5, S62-S72. [CrossRef] [PubMed]

32. Hell, M.M.; Achenbach, S.; Schuhbaeck, A.; Klinghammer, L.; May, M.S.; Marwan, M. CT-based analysis of pericoronary adipose tissue density: Relation to cardiovascular risk factors and epicardial adipose tissue volume. J. Cardiovasc. Comput. Tomogr. 2016, 10, 52-60. [CrossRef] [PubMed] 